Z. klin. Chem. u. klin. Biochem.

9. Jg., S. 117-122, März 1971

\title{
Trennung vom markierten Trijodthyronin und Thyroxin mit Hilfe der Gelfiltrationsmethode
}

\author{
Von G. Gyertyánfy, J. Földes und Eva Kothlin \\ Aus der I. Medipiniscben Universitätsklinik. (Direktor: Prof. Dr. I. Magyar) Budapest, Ungarn
}

(Eingegangen am 19. Oktober 1970)

Die geeignetsten Versucbsbedingungen zar Trennung des im Scrum vorhandenen markierten Trijndthyronins und Thyroxins wurden ermittelt. Die Auswirkung der Dimensionen der Gelfiltrationssäule sowie der Menge der auf das Gelbett aufgetragenen Substanz auf die Trennungsergebnisse warden überprüft. Zugleich wurde die Verlaßlichkeit der Methride anhand von mehreren Modellversuehen kentrolliert. Das von den Autoren ausgearbeitete Verfahren wurde auch in der Praxis, und zwar zur Ermitrlung des Verhältnisses von Trijodthyronin und Thyroxin im Serum von Hyperthyrense-Kranken angewandt. Die Strahlenhelastung der Kranken ist bei Anwendung dieser Methode gering; die Methode eignet sich daher für Routineuntcrsuchungen.

\section{The separation of labelled triindothyronine and tbyroxin by gel filtration}

The optimal conditions for the separation of labelled triiodothyronine and thyroxin in scrum were studied. The effects on the scparation of the dimensions of the get column and the amount of material added wete tested, and the reliability of the method was checked in several model separations. The method used here has been used in practice, e. g., for the determination of the ratio of triindothyronine and thyroxin in hyperthyreotic patients. Since the irradiation dose for the paticne is very low, the method is suitable for routine investigations.

Die Bestimmung des Verhältnisses und der prozentualen Verteilung der in der Peripherie zirkulierenden Schilddrüsenhormone - des Thyroxins und Trijodthyronins - ist theoretisch und praktisch gleich wichtig. Die dafür ursprünglich verwendeten papierchromatographischen und dünnschichtenchromatographischen Verfahren haben den Nachteil, daß die crwähnten VeIbindungen vor der chromatographischen Entwicklung aus dern Serum isoliert werden müssen; während dicses Vorganges kommt es mitunter zum chemischen Zerfall, insbesondere zur Dejodierung. TAUROG und Mitarbeiter haben nachgewiesen, daB diese Formone während der papierchromatographischen Entwicklung auch spontan dejodiett werden können $(1,2)$. Daher suchte man neue Methoden zur Trennung dieser. Hormone und begann hierzu in letzter Zeit die Gelfiltrationsmethode heranzurichen (3-6).

Eine det Grundlagen der Gelfiltrationsmethode bildet der Molekularsiebeffekt der Gele. Außerdem werden die einzelnen Verbindungen unterschiedlich adsotbiert, die Trennung wird daher von beiden Faktoren beeinflußt. Zwischen den Molekulardimensionen des Thyroxins und Trijodthyronins und ihrem Adsorptionsvermögen besteht kein Größenunterschied (7), so daß ihre Trennung nur mit Hilfe einer größcren Sâule vorgenommen werden kann.

Von den Versuchen Mongey's und Mason's (3) ausgehend untersuchten wir, welche Gelfiltrationsmethode sich zur Trennung des markierten Trijodthyronins und Thyroxins am besten eignet, und welche Versuchsbedingungen die zweckmäßigsten sind. Dic crzielten Ergebnisse haben wir auch in der Praxis angewandt.

\section{Methodik und Versuchsergebnisse}

Reagenzien

Sephadex G-25 "fine“, Dextrangcl (Pharmacia, Uppsala)

125. I-Trijodthyronin und 125I-Thyroxin (Philips-Duphar)

125I-Minnojodtyrosin und ${ }^{125}$ I-Dijodtyrosin (Philips-Duphar) $0,01 \mathrm{~N} \mathrm{NaOH}$

„Fractionat", autromatischer Fraktionssammler (,Labor" MIM) GOM NK-108, encrgicscicktiver Zäblet.

Heratellung der Gelfiltrationssäule

Das Sephadex G-25 Dextrangel wird in 0,1 N NaOH suspendicrt, drcimal dekantiert, und aus diesce Suspension nach $24 \mathrm{stdg}$. Stchen die Gelfiltrationssäule hergcstellt.

Gelfiltration des markierten Trijodthyronins und Thyroxins

Zur Untersuchung wurde cire $25 \mathrm{~cm}$ lange Säule mit cincm Durchmesser von $1,5 \mathrm{~cm}$ verwendet. Aus dem markierten Isotopenpräparat wurde mit $0,01 \mathrm{~N} \mathrm{NaOH}$ einc Lösung mit det spczifischen Aktivität von $0,1 \mu \mathrm{C} / \mathrm{ml}$ angefertigt; $1 \mathrm{~m} /$ dieser I_ösung wurde auf das Gelhett aufgetragen, und $1 \mathrm{ml}$ diente als Standard. Nachdem die aufgetragene Lösung ins Gel eingezogen war, wurde mit $5 \mathrm{ml}$ $0,01 \mathrm{~N} N a O H I$ nachgewaschen und dafür gesorgt, daß dic Waschflüssigkeit abtropfte. Nachher wurde die Sãule auf den automatischen Praktionsammler gebracht, und dic Elution mit $0,01 \mathrm{~N}$ $\mathrm{NaOH}$ durchgeführt.

Wahrend der Gelfilration sammelten wir $505 \mathrm{~m}$-Fraktioncn, deren Aktivitat im Brihrlochkristall mit Illife des energiesclektiven Zählers gemesien wurde.

Dic Ergebnisse unserer Messungen werden in Tabelle 1 veranschaulicht. Aus dicser Tabcllc geht hervor, daß die Wiederfindung vollständig ist.

Bei der Gelfiltration des markicrten Trijodthyronins gewannen wir cin Chromatogramm, das \%wci Gipfel enthiclt. Der crste, kleine Gipfel entsprach dem an- 
Tab. 1

Gelfiltration von ${ }^{125} I-T r i j o d t h y r o n i n ~ u n d ~{ }^{125}[-T h y r o x i n$ auf einer ₹ $1,5 \mathrm{~cm}$ großen Săule

Die angegebenen Werte sind Durchschnittsergebnisse von je 5 Versuchen

\begin{tabular}{|c|c|c|c|c|}
\hline Verbindung & Angaben & $\begin{array}{c}\bar{X} \\
0, n \\
0, n\end{array}$ & $\begin{array}{c}\text { Bereich } \\
\%\end{array}$ & $\mathrm{~S}_{\overline{\mathbf{x}}}$ \\
\hline $\begin{array}{l}\text { 125I-Triiod- } \\
\text { thyrnni- }\end{array}$ & $\begin{array}{l}\text { Wiederfindung } \\
I^{-} \\
\text {126I-Trijodthyronin } \\
\text { '261-T!y"nxi- }\end{array}$ & $\begin{array}{r}98,24 \\
2,66 \\
95,98 \\
1.22\end{array}$ & $\begin{array}{c}97,54-98,91 \\
1,44-4,55 \\
91,80-98,53 \\
0-3,65\end{array}$ & $\begin{array}{l} \pm 0,40 \\
\pm 1,30 \\
\pm 1,33 \\
\pm 1,22\end{array}$ \\
\hline $\begin{array}{l}\text { 1251-Thy- } \\
\text { roxin }\end{array}$ & $\begin{array}{l}\text { Wiejerfindung } \\
\text { I- } \\
\text { 125I-Trijodthyronin } \\
\text { 125I-Thyroxin }\end{array}$ & $\begin{array}{r}101,69 \\
7,90 \\
3,86 \\
88,20\end{array}$ & $\begin{array}{c}99,40-102,94 \\
4,84-11,83 \\
2,47-5,26 \\
82,90-92,69\end{array}$ & $\begin{array}{l} \pm 1,15 \\
\pm 2,06 \\
\pm 0,81 \\
\pm 2,86\end{array}$ \\
\hline
\end{tabular}

organischen Jodid, der zweite, der die aufgetragene Substanzmenge fast ganz einschloß, entsprach dem markierten Trijodthyronin. Bei der Gelfiltration des markierten Thyroxins kam ebenfalls ein zwei Gipfel enthaltendes Chromatogramm zustande, von denen der erste, kleine 'Gipfel wieder das anorganische Jodid, der zweite, größere das anwesende markierte Thyroxin bedeutete. Bei der Gelfiltration beider Verbindungen konnte in geringfügiger Menge eine Thyroxinverunreinigung im Trijodthyronin bzw. eine Trijodthyroninverunreinigung im Thyroxin nachgewiesen werden.

Trennung des Gemisches von 125I-Trijodthyronin und ${ }^{125} \mathrm{I}$ - Thy roxin

Nachdem die Gelfiltrationsentwicklung des 125I-Trijodthyronins und 125I-Thyroxins erfolgreich war, nahmen wir die Trennung des Gemisches dieser zwei Verbindungen in Angriff. Zwei Fragen beschäftigten uns vor allem:

1. Wie lang muß die Säule sein, um eine optimale Trennung zu erzielen?

2. Welche Substanzmenge läßt sich, unter Beibehaltung einer optimalen Trennung maximal auf das Gelbett auftragen? Diese Frage ist deshalb wichtig, da es bei Erhöhung der aufgetragenen Substanzmenge möglich ist, die spezifische Aktivität zu vermindern.

$\mathrm{Zu}$ Beginn unserer Versuche gingen wir wie oben vor und bedienten uns einer $25 \mathrm{~cm}$ langen Säule mit einem Durchmesser von $1,5 \mathrm{~cm}$ sowie $0,01 \mathrm{~N} \mathrm{NaOH}$. Aus der verdünnten ${ }^{125}$ I-Trijodthy- ronin- und ${ }^{125 I-T h y r o x i n-S t a m m l o ̈ s u n g ~ f e r t i g t e n ~ w i r ~ e i n ~ G e m i s c h ~}$ mit der spezifischen Aktivität von $0,07-0,2 \mu \mathrm{C} / \mathrm{ml}$ an, von dem wir $1 \mathrm{~m} l$ auf das Gelbett auftrugen, $1 \mathrm{ml}$ diente als Standard. Die 125I-Trijodthyronin- und 125I-Thyroxin-Menge wurde so eingestellt, daß ihr Verhältnis zueinander annähernd $1: 1$ betrug. Weiterhin gingen wir wie oben vor.

Der obere Teil von Tabelle 2 und Abbildung 1 veranschaulichen unsere Ergebnisse. Das gewonnene Chromatogramm enthält drei Gipfel. Der erste, kleinere Gipfel bedeutet das anwesende anorganische Jodid, der zweite entspricht dem 125I-Trijodthyronin und der

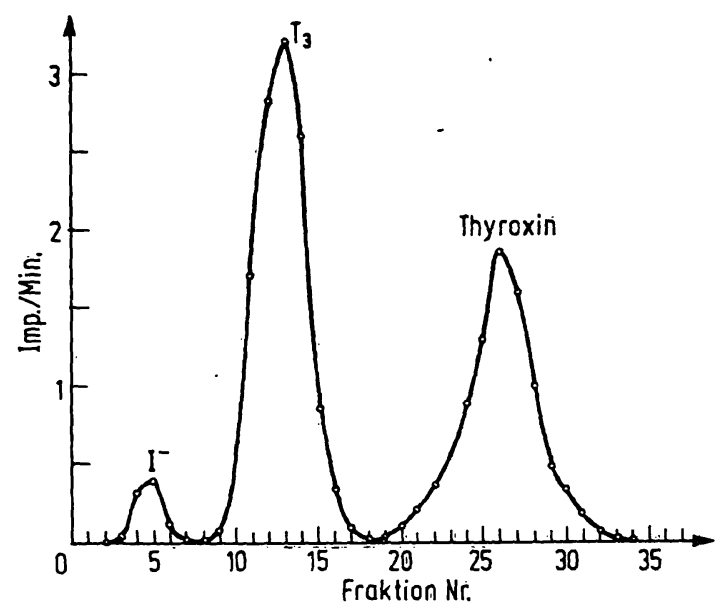

Abb. 1

Elutionsdiagramm eines Gemisches von Trijodthyronin und Thyroxin

dritte dem ${ }^{125}$-Thyroxin. Aus Tabelle 2 ist ersichtlich, $\mathrm{da} B$ zwischen der prozentualen Menge des aufgetragenen und eluierten 125I-Thyroxins und 125I-Trijodthyronins, obwohl die Wiederfindung vollständig ist, eine sehr große Abweichung besteht. Aufgrund der $t$-Verteilung nahmen wir auch statistische Berechnungen vor, um zu ermitteln, wieviel Prozent die Wahrscheinlichkeit besitzt, $\mathrm{da} \beta$ die Abweichung den $\pm 5 \%$-Wert überschreitet. Nach unseren Berechnungen ergab sich dies mit einet Wahrscheinlichkeit von $99 \%$, woraus hervorgeht, daß sich $25 \mathrm{~cm}$ lange Säulen mit einem Durchmesser von $1,5 \mathrm{~cm}$ nicht für unsere Zwecke eignen.

In det Folge verwendeten wir zur Trennung des genannten Gemisches eine $35 \mathrm{~cm}$ lange Säule mit einem Durchmesser von

Tab. 2

Trennung des Gemisches von ${ }^{125} \mathrm{I}-$ Trijodthyronin $\left({ }^{128} \mathrm{I}-\mathrm{T}_{3}\right)$ und ${ }^{125} \mathrm{I}-\mathrm{Thyroxin}\left({ }^{125} \mathrm{I}-\mathrm{T}_{4}\right)$

\begin{tabular}{|c|c|c|c|c|c|}
\hline Versuch & $\begin{array}{l}\text { Anzahl der } \\
\text { Versuche }\end{array}$ & Angaben & $\begin{array}{c}\overline{\bar{x}} \\
\%\end{array}$ & $\begin{array}{l}\text { Bereich } \\
\%\end{array}$ & $s_{\overline{\mathbf{x}}}$ \\
\hline \multirow[t]{2}{*}{$\begin{array}{l}\text { Säulendimension: } 23 \times 1,5 \mathrm{~cm} \\
\text { Aufgetragene Substanzmenge: } 1 \mathrm{ml}\end{array}$} & \multirow[t]{2}{*}{20} & \multirow{2}{*}{$\begin{array}{l}\text { Wiederfindung } \\
\text { I- } \\
\text { Differenz zwischen dem aufge- } \\
\text { tragenen und eluierten } 1251-T_{8} \\
\text { Differenz zwischen dem aufge- } \\
\text { tragenen und eluierten } 1201-T_{\text {a }}\end{array}$} & $\begin{array}{r}102,74 \\
1,40 \\
\pm 7,71\end{array}$ & $\begin{array}{c}96,04-105,95 \\
1,26-4,06 \\
0,40-17,49\end{array}$ & $\begin{array}{l} \pm 0,70 \\
\pm 0,10 \\
\pm 1,13\end{array}$ \\
\hline & & & $\pm 7,81$ & $0,40-17,49$ & $\pm 1,04$ \\
\hline \multirow[t]{2}{*}{$\begin{array}{l}\text { Säulendimension: } 35 \times 1,5 \mathrm{~cm} \\
\text { Aufgetragene Substanżmenge: } 1-5 \mathrm{ml}\end{array}$} & \multirow[t]{2}{*}{15} & \multirow{2}{*}{$\begin{array}{l}\text { Wiederfindung } \\
\text { I- } \\
\text { Differenz zwischen dem aufge- } \\
\text { tragenen und eluierten } 120-\mathrm{T}_{3} \\
\text { Differenz zwischen dem aufge-- } \\
\text { tragenen und eluierten 1901-T, }\end{array}$} & $\begin{array}{r}98,47 \\
4,06 \\
+3,10\end{array}$ & $\begin{array}{c}95,16-104,90 \\
2,32-5,37 \\
1,41-5,20\end{array}$ & $\begin{array}{l} \pm 1,06 \\
\pm 0,40 \\
\pm 0,37\end{array}$ \\
\hline & & & $\pm 2,57$ & $0,24-5,20$ & $\pm 0,55$ \\
\hline \multirow[t]{2}{*}{$\begin{array}{l}\text { Säulendimension: } 45 \times 1,5 \mathrm{~cm} \\
\text { Aufgetragene Substanzmenge: } 5 \mathrm{ml}\end{array}$} & \multirow[t]{2}{*}{5} & \multirow{2}{*}{$\begin{array}{l}\text { Wiederfindung } \\
\text { I- } \\
\text { Differenz zwischen dem aufge- } \\
\text { tragenen und eluierten } 1261-T_{8} \\
\text { Differenz zwischen dem aufge- } \\
\text { tragenen und eluierten } 126 \mathrm{I}-\mathrm{T}_{4}\end{array}$} & $\begin{array}{r}95,21 \\
5,59 \\
\pm 7,38\end{array}$ & $\begin{array}{c}94,10-96,30 \\
3,96-6,10 \\
6,11-8,43\end{array}$ & $\begin{array}{l} \pm 0,81 \\
\pm 0,45 \\
\pm 2,21\end{array}$ \\
\hline & & & $\pm 7,38$ & $6,06-8,52$ & $\quad \pm 1,96$ \\
\hline
\end{tabular}


$1,5 \mathrm{~cm}$. Auf das Gelbett wurde $1 \mathrm{ml}$ der Lösung mit der spezifischen Aktivität von $0,03-0,08 \mu \mathrm{C} / \mathrm{ml}$ aufgetragen, wobei das Verhältnis von Trijodthyronin und Thyroxin nahezu $1: 1$ betrug. Nach Erzielung befriedigender Ergebnisse setzten wir unsere Untersuchung fort, indem wir auch die Prüfung der Wirkung der aufgetragenen Substanzmenge mit einbezogen. Auf die Gelfiltrationssäule wurden $1-5 \mathrm{ml}$ der zu trennenden Substanz aufgetragen.

Das gewonnene Chromatogramm entsprach der Abbildung 1. Die Zahlenwerte werden durch den mittleren Teil von Tabelle 2 veranschaulicht. Bei einer fast vollständigen Wiederfindung übertrifft der Unterschied zwischen der auf das Gelbett aufgetragenen und der eluierten ${ }^{125} \mathrm{I}$-Trijodthyronin- und ${ }^{125} \mathrm{I}$-Thyroxin-Menge den $\pm 5 \%$-Wert nicht. Auch die aufgrund der tVerteilung vorgenommenen statistischen Berechnungen bestätigen diese Feststellung mit 99\% Wahrscheinlichkeit.

Zur Trennung von Trijodthyronin und Thyroxin erweisen sich also $35 \mathrm{~cm}$ lange Säulen mit einem Durchmesser von $1,5 \mathrm{~cm}$ als am geeignetsten.

Bei der Fortsetzung unserer Versuche änderten wir das Verhältnis von Trijodthyronin und Thyroxin, das wir auf die Werte 1:2 und 2:1 einstellten. In jedem Fall exzielten wir entsprechende Ergebnisse.

Endlich führten wir die Untersuchungen bei gleichen Versuchsbedingungen ergänzend auch mit einer $45 \mathrm{~cm}$ langen Säule mit einem Durchmesser von $1,5 \mathrm{~cm}$ durch. Wir trugen auf die Säule $5 \mathrm{ml}$ eines Gemisches auf, in dem das Verhältnis von Trijodthyronin zu Thyroxin $1: 1$ betrug.

Die Ergebnisse lassen sich im unteren Teil der Tabelle 2 ablesen. Zwischen der prozentualen Menge des aufgetragenen und eluierten Trijodthyronins und Thyroxins ergab sich jedoch in jedem einzelnen Fall eine größere Abweichung als $\pm 5 \%$, so daß auch diese Säule unsersen Zwecken nicht entspricht.

Trennung von ${ }^{125} \mathrm{I}-\mathrm{Trijod}$ thyronin und ${ }^{125} \mathrm{I}-$ Thyroxin aus Serum

Hierauf wandten wir uns dem eigentlichen Zweck unserer Untersuchungen, der Trennung des im Serum anwesenden markierten Trijodthyronins und Thyroxins, zu.

Zu diesem Zweck setzten wir dem Serum cin Trijodthyronin- und Thyroxin-Gemisch von verschiedenem Verhältnis $(1: 1,1: 2,2: 1)$ zu und inkubierten das so erhaltene Gemisch 1 Std. bei $37^{\circ}$; dann gaben wir $0,01 \mathrm{~N} \mathrm{NaOH}$ zu und inkubierten das Gemisch eine weitere Stunde bei $37^{\circ}$. Nachher trugen wir $5 \mathrm{ml}$ des Gemisches auf das $35 \times 1,5 \mathrm{~cm}$ große Dextranbett auf, während andere $5 \mathrm{~m} /$ als Standard dienten. Die Elution von der Säule und die Messung wurden wie oben beschrieben vorgenommen.

Das so erhaltene Chromatogramm enthält $4 \mathrm{Gipfel,} \mathrm{wie}$ aus Abbildung 2 hervorgeht. Der erste Gipfel entspricht dem an Eiweiß gebundenen Jod, der zweite dem anorganischen Jodid, der dritte dem markierten Trijodthyronin und der vierte Gipfel dem markierten Thyroxin.

Die Zahlenwerte wurden in Tabelle 3 zusammengefaßt. Aus den Daten ist ersichtlich, daß sich die $35 \times 1,5 \mathrm{~cm}$ große Säule zur. Trennung des im Serum anwesenden markierten Trijodthyronins und Thyroxins eignet.

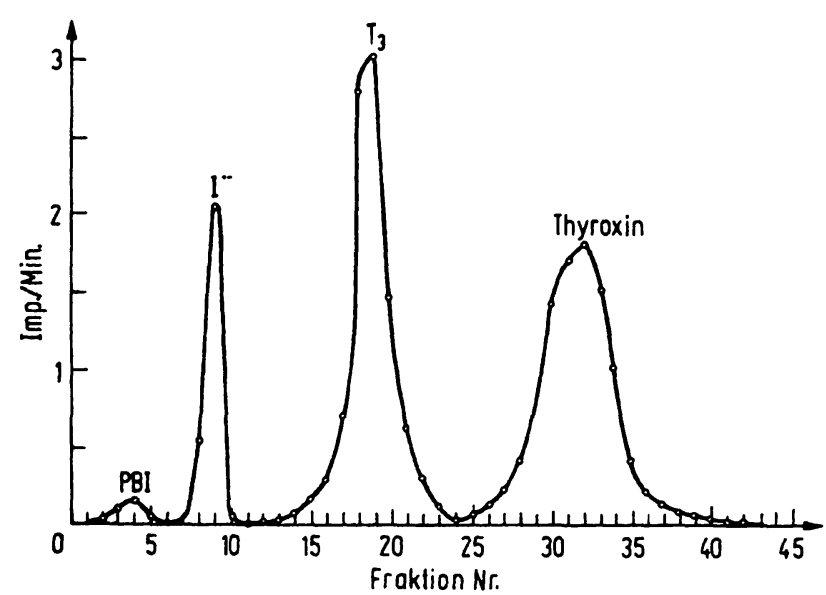

Abb. 2

Elutionsdiagramm des mit Serum inkubierten Gemisches von Trijodthyronin und Thyroxin

Tab. 3

Trennung des Gemisches von mit Serum inkubierten ${ }^{128}$ I-Trijodthyronin $\left({ }^{128}\left[-T_{3}\right)\right.$ und $\left.{ }^{126}\right]-$ Thyroxin $\left(128 I-T_{4}\right)$ ) als Durchschnittsergebnis

\begin{tabular}{|c|c|c|c|}
\hline Angaben & $\begin{array}{l}\overline{\mathbf{x}} \\
\%\end{array}$ & $\underset{\%}{\text { Bereich }}$ & $S_{\bar{x}}$ \\
\hline Wiederfindung & 99,46 & $95,76-104,54$ & +0.91 \\
\hline PBI & 2,54 & $1,15-4,91$ & $\pm 0,53$ \\
\hline $1^{-}$ & 7,41 & $0,42-8,82$ & $\pm 0,44$ \\
\hline $\begin{array}{l}\text { Differenz zwischen dem aufge- } \\
\text { tragenen und eluierten } \\
126 \mathrm{I}_{3}\end{array}$ & $\pm 1,69$ & $0,17-3,51$ & \pm 0.68 \\
\hline $\begin{array}{l}\text { Differenz zwischen dem aufge- } \\
\text { tragenen und eluierten } \\
1251-\mathrm{T}_{4}\end{array}$ & $\pm 1,16$ & $0,15-4,28$ & $\pm 0,79$ \\
\hline
\end{tabular}

Kontrolle der Verläßlichkeit der Methode

Im Serum sind außer Trijodthyronin und Thyroxin auch Monojodtyrosin und Dijodtyrosin anwesend; wir hielten es daher für notwendig zu kontrollieren, ob diese nicht die Trennung von Trijodthyronin und Thyroxin beeinflussen. Außerdem überprüften wir mit Hilfe einer anderen Trennungsmethode die Richtigkeit der mittels des Gelfiltrationsverfahrens gewonnenen Angaben. $\mathrm{Zu}$ diesem $\mathrm{Zweck}$ führten wir die folgenden Untersuchungen durch:

1. Untersuchung des Einflusses von Monojodtyrosin und Dijodtyrosin.

2. Kontrolle der mit Gelfiltration gewonnenen Ergebnisse anhand des papierchromatographischen Verfahrens.

\section{Untersucbung des Einflusses von Monojodtyrosin und Dijod- tyrosin}

Zunächst nahmen wir die Gelfiltration des reinen ${ }^{125} \mathrm{I}-\mathrm{M}$ onojodtyrosins bzw. des ${ }^{125} \mathrm{I}-\mathrm{Dij}$ odtyrosins auf einer $35 \times 1,5 \mathrm{~cm}$ großen Säule vor. Aus der Stammlösung der markierten Tyrosine stellten wir mit $0,01 \mathrm{~N} \mathrm{NaOH}$ eine Lösung mit der spezifischen Aktivität von $0,02 \mu \mathrm{C} / \mathrm{m} /$ her, von der wir $5 \mathrm{~m} l$ auf das Gelbett auftrugen, während $5 \mathrm{ml}$ als Standard dienten. Elution und Messung wurden auf die übliche Art und Weise durchgeführt.

Das gewonnene Chromatogramm wies einen einzigen großen Gipfel auf, der dem markierten Mono- oder Dijodtyrosin und dem mit diesen gemeinsam eluierten anorganischen Jodid entsprach. 


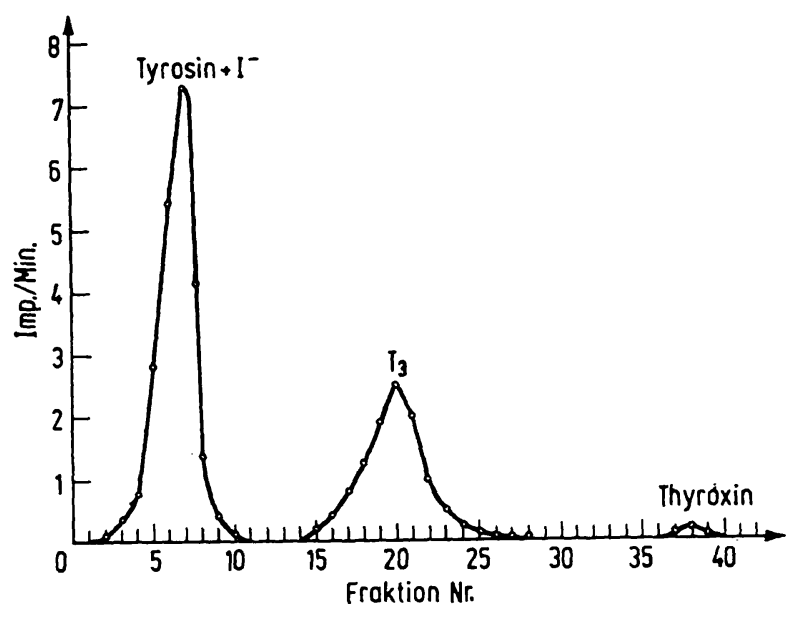

Abb. 3

Elutionsdiagramm des Gemisches von Tyrosinen und Trijodthyronin

Hierauf stellten wir aus dem markierten Tyrosin und dem markierten Trijodthyronin ein Gemisch im Verhältnis 2:1 her, von dem wir $5 \mathrm{ml}$ auf die Gelfiltrationssäule auftrugen, um im folgenden auf die übliche Art und Weise vorzugehen

Unsere Messungen ergaben das in Abbildung 3 veranschaulichte Chromatogramm. Dieses weist zwei Gipfel auf; der erste Gipfel entspricht dem markierten Tyrosin und dem mit diesem gleichzeitig abgelösten anorganischen Jodid, der zweite Gipfel entspricht dem markierten Trijodthyronin.

Tab. 4

Gelfiltrationsergebnisse von ${ }^{125}$ I-Monojodtyrosin (M ${ }^{125} I T$ ) und ${ }^{125} \mathrm{I}-$ Dijodtyrosin (D'2siT)

\begin{tabular}{|c|c|c|}
\hline Versuche & Angaben & $\begin{array}{l}\bar{x} \\
\%\end{array}$ \\
\hline Gelfiltration von $M^{125} \mathrm{IT}$ & $\begin{array}{l}\text { Wiederfindung } \\
M^{125} I T+I^{-}\end{array}$ & $\begin{array}{l}98,89 \\
99,25\end{array}$ \\
\hline $\begin{array}{l}\text { Gelfiltration des Gemisches } \\
\text { von. } M^{125} \mathrm{IT} \text { und }{ }_{125} \mathrm{I}_{3}\end{array}$ & $\begin{array}{l}\text { Wiederfindung } \\
M^{125}+I^{-} \\
\text {Differenz zwischen aufgetrage- } \\
\text { nem und eluiertem } M^{125} I T \\
\text { Differenz zwischen aufgetrage- } \\
\text { nem und eluiertem }{ }^{125 I}-T_{3}\end{array}$ & $\begin{array}{r}98,25 \\
60,98 \\
+2,88 \\
\pm 2,83\end{array}$ \\
\hline Gelfiltration von $D^{125} 1 \mathrm{~T}$ & $\begin{array}{l}\text { Wiederfindung } \\
\mathrm{D}^{125} 1 \mathrm{~T}+\mathrm{I}^{-}\end{array}$ & $\begin{array}{l}97,88 \\
98,87\end{array}$ \\
\hline $\begin{array}{l}\text { Gelfiltration des Gemisches } \\
\text { von } D^{125} I T \text { und }{ }_{125} I-T_{3}\end{array}$ & $\begin{array}{l}\text { Wiederfindung } \\
D^{125} 1 \mathrm{~T}+\mathrm{I}^{-} \\
\text {Differenz zwischen aufgetrage- } \\
\text { nem und eluiertem } \mathrm{D}^{125} \mathrm{IT} \\
\text { Differenz zwischen aufgetrage- } \\
\text { nem und eluiertem }{ }^{125} \mathrm{~T}_{3}\end{array}$ & $\begin{array}{r}96,69 \\
63,15 \\
+3,08 \\
+2,95\end{array}$ \\
\hline
\end{tabular}

Die Zahlenwerte sind aus Tabelle 4 ersichtlich. Das markierte Mono- und Dijodtyrosin wurde zugleich mit dem anorganischen Jodid eluiert. Die Menge der auf das Gelbett aufgetragenen und von diesem abgelösten Tyrosine war innerhalb der Versuchsfehlergrenze identisch, so daß ihre Anwesenheit die Trennung der Thyronine nicht beeinflußt.

Endlich kontrollierten wir mit Hilfe der Isotopendoppelmarkierung, ob die markierten Tyrosine tatsächlich zugleich mit dem anorganischen Jod eluiert werden. Zu diesem Zweck unterzogen wir die mit ${ }^{125}$ I markierten Tyrosine, nach Vermischen mit $\mathrm{Na}^{131}$, der Gelfiltrationsmethode.

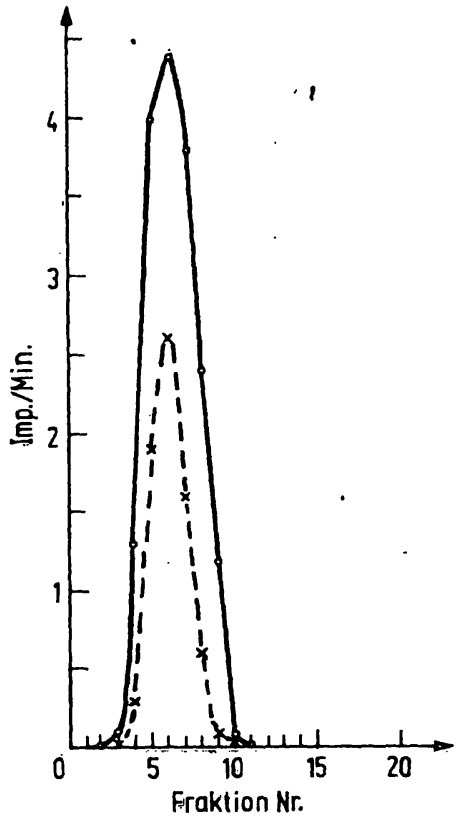

Abb. 4

Elutionsdiagramm des Gemisches von anorganischem Jod $(x--x)$ und Tyrosinen (--.)

Das in Abbildung 4 veranschaulichte Chromatogramm zeigt, daß das anorganische Jod tatsächlich in einem Gipfel mit den markierten Tyrosinen eluiert wird.

Das im Serum anwesende Mono- und Dijodtyrosin stören also die Trennung und Bestimmung des Trijodthyronins und Thyroxins nicht.

\section{Kontrolle der mit Gelfiltration gewonnenen Ergebnisse anband des papierchromatographischen Verfabrens}

Nachdem erwiesen war, daß die im Serum anwesenden Tytosine die Trennung der Thyronine nicht stören, kontrollierten wir papierchromatographisch die mittels Gelfiltrationsmethode gewonnenen Ergebnisse der Trijodthyronin-Thyroxin-Trennung. Wir stellten für die Papierchromatographie und die Gelfiltration ein gemeinsames Gemisch aus markiertem Trijodthyronin her. Die papierchromatographische Entwicklung nahmen wir nach Roche und Mitarbeitern (8) sowie KerTaI und Mitarbeitern (9) vor. Als Trennungsmedium wurden $\mathrm{n}-\mathrm{Butanol}$ und $2 \mathrm{~N} \mathrm{NH}_{4} \mathrm{OH}$ verwendet. Für die Papierchromatographie stellten wir eine Lösung mit der speziffschen Aktivität von $15-20 \mu \mathrm{C} / \mathrm{m} l$ her, die wir mit $0,01 \mathrm{~N} \mathrm{NaOH}$ auf die der Gelfiltration entsprechende spezifische Aktivität verdünnten.

Die Ergebnisse der Vergleichsmessunger werden in Tabelle 5 veranschaulicht. Die mit beiden Methoden gewonnenen Werte stimmen gut überein.

Tab. 5

Trennungsergebnisse des Gemisches von ${ }^{225} I-T r i j o d t h y r o n i n ~\left({ }^{125} I-T_{3}\right)$ und ${ }^{126}{ }_{I}-T h y r o x i n\left({ }^{126} I-T\right.$, bei Anwendung der Gelfiltrations- und de papierchromatographischen Methode

\begin{tabular}{|c|c|c|c|c|}
\hline \multirow[b]{2}{*}{$\begin{array}{c}\text { Verhältnis } \\
\text { von } \\
T_{3} \text { zu } T_{4}\end{array}$} & \multirow[b]{2}{*}{ Verbindung } & \multirow[b]{2}{*}{$\begin{array}{c}\text { Eingesetzte } \\
\text { Substanz } \\
(\%)\end{array}$} & \multicolumn{2}{|c|}{$\begin{array}{c}\text { Wiedergefundene Substanz } \\
(\%)\end{array}$} \\
\hline & & & $\begin{array}{l}\text { Nach } \\
\text { Gelfiltration }\end{array}$ & $\begin{array}{l}\text { Nach } \\
\text { Papierchro- } \\
\text { matographie }\end{array}$ \\
\hline \multirow[t]{2}{*}{$1: 1$} & ${ }^{128} \mathrm{I}-\mathrm{T}_{3}$ & 51,83 & 48,71 & 52,27 \\
\hline & ${ }^{228} \mathrm{I}-\mathrm{T}$ & 45,53 & 46,69 & 48,08 \\
\hline \multirow[t]{2}{*}{$2: 1$} & ${ }^{125} \mathrm{I}-\mathrm{T}_{\mathrm{z}}$ & 67,94 & 65,67 & 68,13 \\
\hline & ${ }^{1285} \mathrm{I}-\mathrm{T}_{4}$ & 32,84 & 33,77 & 36,85 \\
\hline \multirow[t]{2}{*}{$1: 2$} & ${ }^{225} \mathrm{I}-\mathrm{T}_{\mathrm{s}}$ & 34,05 & 37,30 & 38,13 \\
\hline & ${ }^{228} \mathrm{I}-\mathrm{T}$ & 60,95 & 57,80 & 61,27 \\
\hline
\end{tabular}




\section{Wie lange dauert bei Ihnen}

\section{eine wahre Glukose-Bestimmung?}

\section{Wir benötigen nur 10 Sekunden ...}

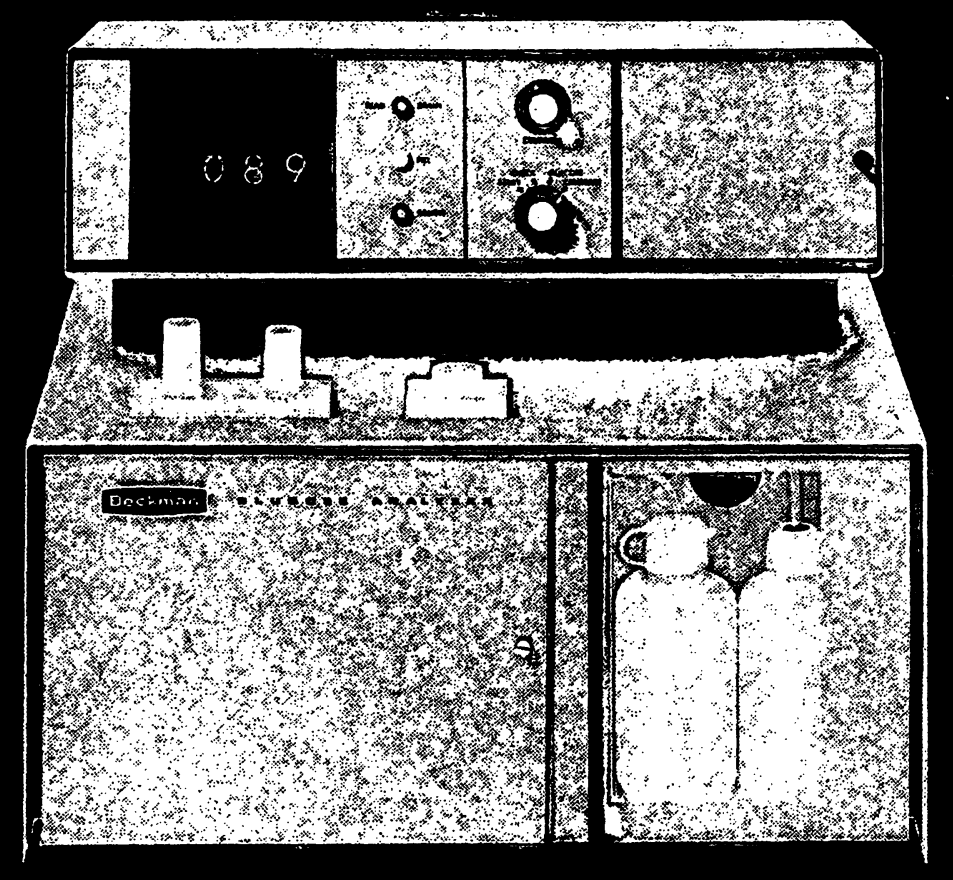

... mit dem neuen Beckman-Glukose-Analysator Modell ERA-2001 durch Anwendung einer völlig neuen Meßtechnik.

Unser Gerät ermittelt die wahre Glukose durch polarographische Messung der Abnahmegeschwindigkeit des Sauerstoffs während der enzymatischen Oxydation.

Weitere überzeugende Argumente:

2) Mikroliter-Proben

$10 \mu$ l Serum oder Plasma bzw. $50 \mu l$ Urin

(2) Ohne Enteiweißung oder Probenverdünnung
(-) Digitale Anzeige der Meßwerte in $\mathrm{mg} \%$ Glukose

(2) Meßgenauigkeit $\pm 2 \%$ Linearität der Anzeige bis $400 \mathrm{mg} \%$

(2) Außerordentlich günstiger Preis

\section{Beckman}

BECKMAN INSTRUMENTS GMBH 8 München 45, Frankfurter Ring 115, Tel.38871, Telex 05-23823

Technische Büros: Berlin, Tel. 3121035 ; Hamburg. Tel. 5195 54: Hannover, Tel. 6639 92; Düsseldori, Tel. 68 44 93; Franklurt, Tol. (06103) 10 03; Stuttgart, Tel. 71 18 37; München, Tol. 885035

Internationale Niederlassungen: Fullerton/USA, Genf, Paris.

Glenrothes/Schottland, Toklo, Kapotadt, Wien, Amsterdam, Stockholm 


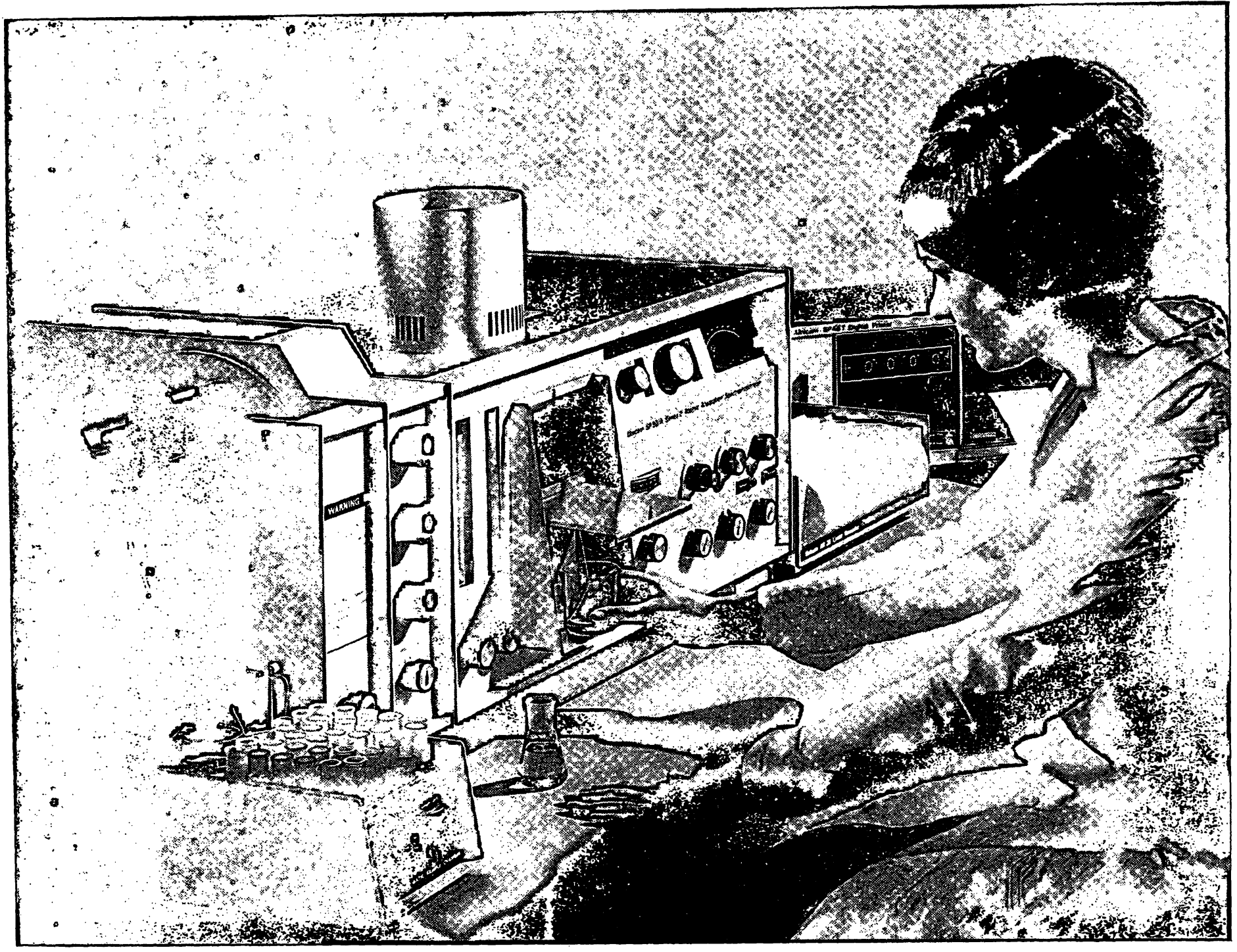

\section{Seien Sie anspruchsyoller bei lhren Forschungs- und Routinearbeiten}

nützen Sie die neuesten Möglichkeiten aus dem Programm PYE UNICAM

Das weiterentwickelte AtomabsorptionsSpektralphotometer SP 90 Serie 2 basiert auf dem Prinzip des bekannten SP 90 . Es bietet Ihnen neue Vorteile durch seine lineare Extinktions-Anzeige, die kontinuierliche Skalendehnung, eine neue Lachgasbrenner-Einheit und die eingebaute Flammen-Emissions-Einheit. Zahlreiches Zubehör erweitert die Möglichkeiten: ein automatischer Probenwechsler, eine digitale Anzeige- und Drucker-Einheit, ein Lampenwechsler und ein Mehrschlitzbrenner.
Wellenlängenbereich $190 \mathrm{~nm}$ bis $770 \mathrm{~nm}$ bzw. $190 \mathrm{~nm}$ bis $852 \mathrm{~nm}$; Anschluß für Schreiber.

Anwendung: Agri-Kultur-Chemie, Biochemie, klinische Chemie, Galvanik, Nahrungsmittel, Baumaterialien, allgemeine Industrie-Chemie, Geologie, Metallurgie, Petro-Chemie, Kunststoffe, Wasser-Analysen, Textilien. Damit erschließt die Atomabsorptions-Technik der Analytik neue Möglichkeiten. In den Anwendungslaboratorien in Hamburg und Cambridge werden ständig neue Methoden ausgearbeitet.
Bitte fordern Sie ausführliches Informationsmaterial an. Es liegt für Sie bereit.

Philips Elektronik Industrie $\mathrm{GmbH}$ 2000 Hamburg 63 - Röntgenstraße 22 Telefon (0411) 501031

Telefon-Nummern der Büros in: Berlin (0311) 245908 , Bielefeld (0521) 230 81. Dortmund (0231) 41961 , Düsseldort (0211) 346051

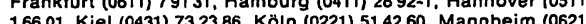
4201 . München (0811) 76791 Nürnerg (0911) 464763 , Stulgar (0711) $589081-83$.

Analysengeräte

Wir interessieren uns für das Spektralphotometer SP 90 Serie 2 und bitten um

$\square$ Zusendung ausführlicher Unterlagen ein Angebot

Besuch Ihres Beratungsingenieurs

Gewünschtes bitte ankreuzen oder ergänzen 
Tab. 6

In vivo-Ergebnisse der Trennung und Bestimmung von markiertem Trijodthyronin $\left(T_{2}\right)$ und $T h y r o x i n\left(T_{4}\right)$

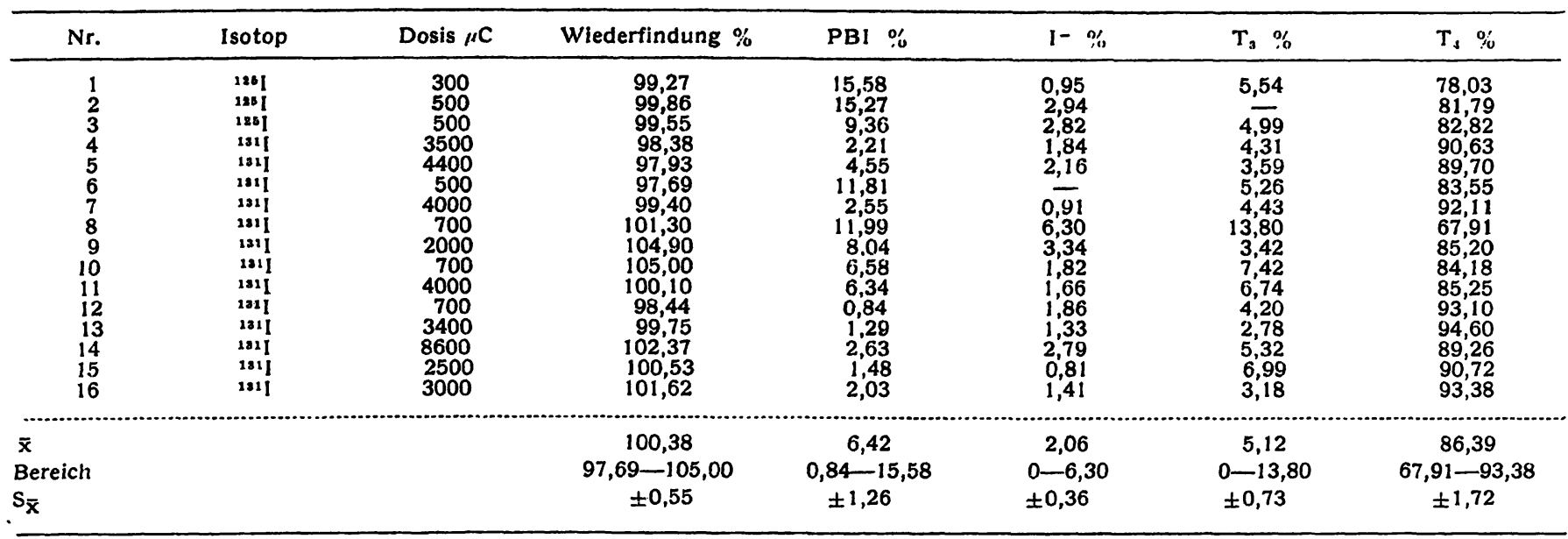

Bestimmung der Trennung und prozentualen Verteilung des markierten Trijodthyronins und Thyroxins in vivo

Um die gewonnenen Ergebnisse in der Praxis anzuwenden, bestimmten wir die prozentuale Verteilung des im Serum von einigen Kranken mit Hyperthyreose anwesenden Trijodthyronins und Thyroxins.

Zu diesem Zweck ließen wir die Kranken - je nach dem, was für eine Untersuchung oder Isotopentherapie notwendig war eine die Isotopen ${ }^{125}$ I oder ${ }^{131}$ I enthaltende Lösung trinken, um $48 \mathrm{Stdn}$. später Blut zu entnehmen. Das Serum wurde mit 0,01N $\mathrm{NaOH}$ im Verhältnis $1: 1$ verdünnt und dann eine Stunde lang bei $37^{\circ}$ inkubiert. Aus dem Inkubat übertrugen wir $5 \mathrm{ml}$ auf eine $35 \times 1,5 \mathrm{~cm}$ große Gelfiltrationssäule, $5 \mathrm{~m} l$ dienten als Standard. Elution und Messung exfolgten auf die oben beschriebene Art und Weise.

Die so gewonnenen Chromatogramme sind von identischem Charakter und gleichen der in Abbildung 2 veranschaulichten Kurve. Das Chromatogramm besteht aus 4 Gipfeln, die dem an das Eiweiß gebundenen Jod, dem anorganischen Jodid, dem markierten Trijodthyronin und Thyroxin entsprechen. Die Zahlenwerte sind in Tabelle 6 zusammengefaßt. Die gewonnenen Angaben stimmen mit den im Schrifttum veröffentlichten Werten gut überein.

\section{Diskussion}

Zur Trennung der im Serum anzutreffenden Schilddrüsenhormone verwendeten wir insbesondere Papierund Dünnschichtenchromatographie. Bei Anwendung dieser Methoden ist bis zu einem gewissen Grad mit Dejodierung zu rechnen. Sie haben ferner den Nachteil, $\mathrm{da} \beta$ sie mit kleinen Substanzmengen arbeiten (max. $0,1 \mathrm{~m} /$ ), so daß es einer Ausgangssubstanz von großer spezifischer Aktivität bedarf. Das bedeutet jedoch bei diagnostischen, d. h. Untersuchungen in vivo, daß eine große Aktivität von Isotopen zur Anwendung gelangt, oder aber, daß die Kranken einer großen Strahlenbelastung ausgesetzt werden müssen. Zur Vermeidung dieser Nachteile bedienten sich in letzter Zeit mehrere Autoren der Gelfiltrationsmethode. Diese hat den großen Vorteil, daß viel mehr Untersuchungsmaterial als bei den bisherigen Methoden auf das Gelbett aufgetragen werden kann, und daher eine Ausgangssubstanz von kleinerer spezifischer Aktivität erforderlich ist.

Die bisher beschriebenen Gelfiltrationsmethoden hatten jedoch mehrere Nachteile. Makovetz, Müller und SpITZY (5) verwendeten zur Trennung des markierten Trijodthyronins und Thyroxins eine $60 \times 0,27 \mathrm{~cm}$ bzw. $110 \times 0,27 \mathrm{~cm}$ große Säule. Die Anfertigung solcher Säulen und die Durchführung der Gelfiltration beanspruchen sehr große praktische Erfahrungen. GEHRING (10) trennte die markierten Thyronine auf einer $20 \times 1,2 \mathrm{~cm}$ großen Sephadex G-15-Säule. Bei dieser Methode bedarf es einer großen Menge Eluens (500-800 $\mathrm{m} /$ ), und die Gipfel sind nicht so scharf wie bei der Sephadex G-25-Säule. MüLLER (G) verwendete eine $60 \times 1,2 \mathrm{~cm}$ und eine $75 \times 1,2 \mathrm{~cm}$ große Sephadex G-25-Säule, doch fehlte in diesen Fällen ein Teil der Modellversuche.

Bei unseren Versuchen gingen wir von dem Verfahren von Mougey und Mason (3) aus, das wir modifizierten. Nach unseren Angaben lassen sich, wenn die Elution auf einer $35 \times 1,5 \mathrm{~cm}$ großen Sephadex G-25-Säule mit $0,01 \mathrm{~N} \mathrm{NaOH}$ durchgeführt wird, das im Serum anwesende markierte Trijodthyronin und Thyroxin trennen und auch ihre prozentuale Verteilung bestimmen. Anhand von Modellversuchen bestätigten wir, $\mathrm{da} ß$ es auf einer $35 \times 1,5 \mathrm{~cm}$ großen Säule mit einer Abweichung $< \pm 5 \%$ zur Wiederfindung der dem Serum zugesetzten Thyronine kommen kann.

Die beschriebene Methode hat den großen Vorteil, daß $5 \mathrm{ml}$ auf das Gelbett aufgetragen werden können; auf diese Weise ist es möglich, bei Hyperthyreose die Verteilung sowie das Verhältnis des im Serum anwesenden Trijodthyronins und Thyroxins bereits bei Gaben von 300-500 $\mu \mathrm{C}{ }^{126 I}$ zu bestimmen; bei dieser Untersuchung sind die Kranken kciner großen Strahlenbelastung ausgesetzt.

Im Sinne unserer Versuche werden die Trennung und prozentuale Verteilung der im Serum anwesenden 
markierten Thyronine durch die anwesenden Tyrosine nicht gestört. Die Menge des im Serum anwesenden Mono- und Dijodtyrosins läßt sich mit der beschriebenen Methode nicht bestimmen, da diese Verbindungen im Einklang mit der Beobachtung MüLLers (6) zugleich mit dem anorganischen Jodid eluiert werden.

Im folgenden gilt es zu klären, was die Fraktion des proteingebundenen Jod enthält, die bei Gelfiltration nach vorhergegangener Inkubation mit $0,01 \mathrm{~N} \mathrm{NaOH}$ nachweisbar ist. Diese Fraktion kann mit den mit
Hilfe von Butanol extrahierbaren Jodproteinen identisch sein; es ist aber auch möglich, daß bei der alkalischen Inkubation die Jodtyrbsine nicht freigesetzt werden und in demselben Gipfel wie die Jodproteine erscheinen. Gegenwärtig beschäftigen wir uns mit der Prüfung dieser Frage.

Endlich sei noch bemerkt, daß sich die beschriebene Methode auch zur Kontrolle der Reinheit von markierten Trijodthyronin- und Thyroxin-Präparaten eignet.

\section{Literatur}

1. Taurog, A., Endocrinology 73, 45 (1963). - 2. Taurog, A., Endocrinology, 73, 57 (1963). - 3. Mougex, E.H. und J. W. MAson, Analytic. Biochem., 6, 223 (1963). - 4. LissrtzkY, S. und J. Bismutr, Clin. Chim. Acta (Amsterdam), 8, 269 (1963). - 5. Makowetz, E., K. Müller und H. Spitzy, Microchem. J., 10, 194 (1966). - 6. Müller, K., Clin. Chim. Acta (Amsterdam), 17,
21 (1967). - 7. Gyertyánfy, G., J. Földes, I. Krasznat, L. Timár und E. BaranYi, Nuclear Medicine 8, 247 (1969). - 8. Roche, J., R. MTChes, W. WOLFF und J. NUNEZ, Biochim. biophysica Acta (Amsterdam), 19, 308 (1955). - 9. R. BALOGH, I. und P. Kertar, Orv. hétil. (Budapest), 104, 154 (1963). - 10. GeHring, D., Nuclear Medicine 8, 306 (1969).

G. Gyertyánfy First Department of Medicine University Medical School Budapest VIII

Korányi S. u. 2/a

Hungary 